\title{
COMPARISON OF SOURCE SCALING RELATIONS OF EASTERN AND WESTERN NORTH AMERICAN EARTHQUAKES
}

\author{
By P. G. Somerville, J. P. Mclaren, L. V. LeFevre, R. W. Burger, and \\ D. V. HELMBERGER
}

\begin{abstract}
Source scaling relations have been obtained for earthquakes in eastern North America and other continental interiors, and compared with a relation obtained for earthquakes in western North America. The scaling relation for eastern North American earthquakes was constructed from measurements of seismic moment and source duration obtained by the waveform modeling of seismic body waves. The events used include nine events of $m_{b L g}$ magnitude 4.7 to 5.8 that occurred after 1960, and four earlier events with magnitudes between 5.5 and 6.6. The scaling relation for events in other continental interiors was used for comparative purposes and to provide constraints for larger magnitudes. Detailed analysis of the uncertainties in the scaling relations has allowed the resolution of two important issues concerning the source scaling of earthquakes in eastern North America. First, the source characteristics of earthquakes in eastern North America and other continental interiors are consistent with constant stress drop scaling, and are inconsistent with nonconstant scaling models such as that of Nuttli (1983). Second, the stress drops of earthquakes in eastern North America and other continental interiors are not significantly different from those of earthquakes in western North America, and have median values of approximately 100 bars. The source parameters of earthquakes in eastern North America are consistent with a single constant stress drop scaling relation, whereas the source parameters of earthquakes in western North America are much more variable and show significant departures from an average scaling relation in which stress drop decreases slightly with seismic moment.
\end{abstract}

\section{INTRODUCTION}

The use of synthetic seismograms to simulate strong ground motions is becoming an increasingly important approach to the evaluation of ground motions for seismic design (Boore and Atkinson, 1987; Burger et al., 1987a; this volume). This approach is especially pertinent in regions such as eastern North America where earthquakes are relatively infrequent and strong ground motion recordings are correspondingly sparse. The simulation methods entail the use of a source model to specify the level of high-frequency radiation from the source in relation to its seismic moment. At present, there are two principal uncertainties in the description of source characteristics required for the use of these methods in eastern North America. These uncertainties relate to whether earthquakes in eastern North America follow a constant or nonconstant stress drop scaling relation and whether their average stress drops are similar to or higher than those of earthquakes in other regions such as western North America. Unresolved, these issues give rise to uncertainty in the estimation of strong ground motion characteristics using simulation methods. It is therefore important to construct a well-constrained source scaling relation for earthquakes in eastern North America and compare it to the scaling relation for earthquakes in western North America.

\section{SOURCE ScALING}

The far-field displacement spectrum of an earthquake source is characterized by frequency-invariant amplitudes below a corner frequency and decay of amplitudes 
with frequency above the corner frequency (Aki, 1967), as shown schematically in Figure 1. The corner period is proportional to the source duration and is related to the source dimensions using models of spreading rupture on fault surfaces (e.g., Cohn et al., 1982). A source scaling relation (shown as the locus of spectral corners in Figure 1) describes the manner in which the source duration increases as seismic moment increases and can be constructed empirically from measurements of these quantities.

For a given seismic moment, smaller source dimensions give rise to a shorter source duration, a higher corner frequency, and larger ground motion amplitudes above the corner frequency, as shown schematically in Figure 1. This is the effect of increasing stress drop, which is defined by the ratio of fault slip to fault dimensions and may be calculated from the seismic moment and the source duration. The stress drop values thus obtained are dependent on the model that is used to relate these two parameters and are also subject to a very large degree of uncertainty stemming from uncertainties in these two parameters. Also, the ambiguity of the interpretation of source duration due to asperities and multiple ruptures causes a corresponding ambiguity in the interpretation of stress drop.

Stress drops may be calculated from seismic moment and source duration estimates using the model of Cohn et al. (1982), in which rupture duration is assumed to reflect the effects of rupture propagation and dislocation rise time over a circular fault surface embedded in a homogeneous medium. Assuming a rupture speed that is 0.8 times the shear wave velocity of $3.5 \mathrm{~km} / \mathrm{sec}$, the duration $\tau$ (in seconds) of the shear wave pulse, averaged over the angle between the fault plane and the ray path, is related to the fault radius $a$ (in kilometers) by

$$
\tau=0.75 a
$$

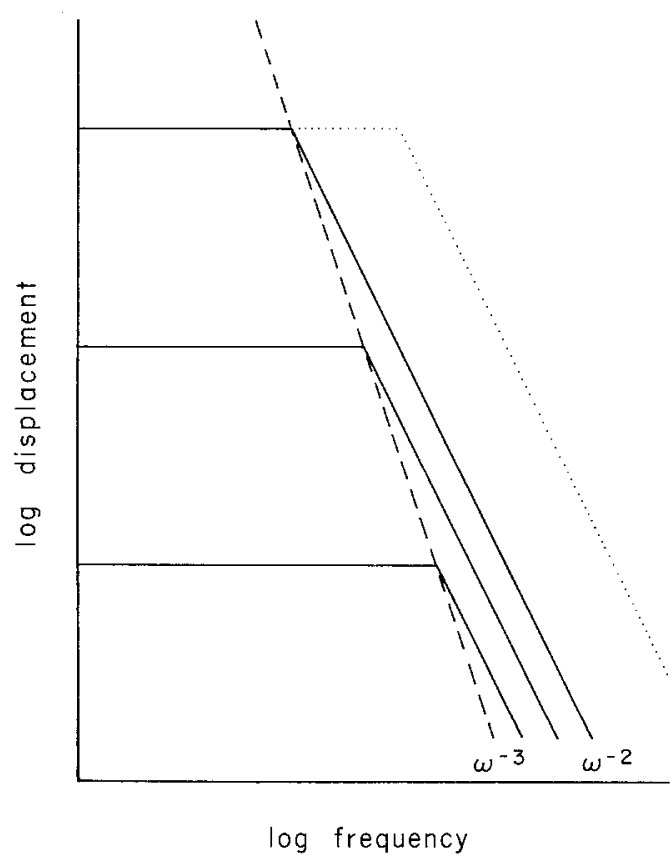

FIG. 1. Schematic diagram of a source scaling model in which the spectral roll-off beyond the corner frequency has a slope of -2 . The locus of spectral corners, shown by a dashed line, has a slope of -3 for the constant stress drop case. The dotted line illustrates the effect on spectral amplitudes at high frequencies of increasing corner frequency (and thereby stress drop) for a given value of seismic moment. 
and the stress drop $\Delta \sigma$ is related to seismic moment $M_{0}$ and duration by

$$
\Delta \sigma=1.87 \times 10^{-22} \cdot M_{0} / \tau^{3} .
$$

This equation is very similar to that of Brune (1970) which is expressed in terms of shear wave corner frequency $f_{c}$ (in Hertz) as

$$
\Delta \sigma=1.97 \times 10^{-22} \cdot M_{0} \cdot f_{c}{ }^{3} .
$$

Taking the logarithm of equation (2),

$$
\log M_{0}=3 \log \tau+\log \Delta \sigma+21.73,
$$

we see that a constant stress drop scaling relation is represented by a line of slope 3 on a log-log spectral plot (Figure 1) and on $\log -\log$ plots of source duration against seismic moment (Figures 7 to 11).

\section{Constant and Nonconstant Stress Drop Scaling Models}

In a study of large earthquakes occurring in seismically active regions of the earth (Kanamori and Anderson, 1975), it was found that stress drop is roughly independent of seismic moment. Although this study did not address the source scaling relations of earthquakes occurring in the interiors of plates such as eastern North America, it led to the expectation that earthquakes in other tectonic environments might also have constant stress drop scaling relationships.

During the past decade, however, it has been suggested by several investigators that stress drop increases with seismic moment for eastern North American earthquakes (Street et al., 1975; Street and Turcotte, 1977). This scaling relation is based on their finding that the seismic moment is proportional to the corner period raised to the fourth power for earthquakes in the moment range of $1.5 \times 10^{19}$ to $6.0 \times 10^{26}$ dyne-cm. The nonconstant stress drop scaling relation was generalized to include mid-plate earthquakes from both continental and oceanic regions by Nuttli (1983a, b) using relationships between seismic moment, surface wave magnitude, and body wave magnitude. This analysis was also applied to plate-margin earthquakes (Nuttli, 1983a), yielding a constant stress drop scaling relation as had been found by previous researchers. In view of this uncertainty in source scaling of eastern North American earthquakes, it is important to resolve whether the stress drop of earthquakes in eastern North America is independent of seismic moment or increases with seismic moment as has been recently suggested.

\section{Differences in Stress Drop between Different Categories of EARTHQUAKES}

The stress drops of intraplate events were found by Kanamori and Anderson (1975) to be higher than those of interplate events by a factor of three on average. Scholz et al. (1985) found a difference of a factor of 6 in a similar study. None of the intraplate events used in these studies occurred in eastern North America, and most occurred close to plate margins and thus in tectonic environments that may be quite different from that of eastern North America and comparable plate interiors. Nevertheless, these studies lead to the expectation that stress drops in continental interiors are higher than those on plate boundaries. 
It has been recently suggested by Kanamori and Allen (1986) that average stress drop is correlated with earthquake repeat time through a mechanism related to asperity size and its dependence on slip rate. The fault slip rate is viewed by them as generalizing previous distinctions between interplate and intraplate earthquakes, and between plate margin and plate interior earthquakes. They suggest that the very long repeat times of earthquakes in regions such as the Eastern United States imply high average stress drops compared with those of earthquakes that have short repeat times. Since some earthquakes in western North America have short repeat times, this suggestion leads to the expectation that on average, stress drops of eastern events may be higher than those of western events. It is therefore important to determine whether this expected difference in stress drop is borne out in the data.

\section{APPROACH}

Scaling relations were constructed from the source parameters of earthquakes from eastern North America, other continental interiors, and western North America. The seismic moments and source durations used in the scaling relationships were estimated from the time-domain modeling of body waves. To provide a basis for evaluating and comparing the scaling relations, uncertainties in them were analyzed using estimates of uncertainty in the seismic moment and source duration values.

Although the waveform modeling approach does have some limitations, these do not include the difficulties that accompany the use of spectral methods for estimating source parameters. These difficulties are attributable to the fact that modification of the corner frequency by wave propagation effects (Barker and Langston, 1986) is not accounted for in the spectral method. The inconsistencies that result from the use of the spectral method on regional recordings have been described by Haar et al. (1984). The success of the waveform modeling approach to estimating source parameters (e.g., Langston and Helmberger, 1975) is demonstrated by studies in which close-in, regional, and teleseismic body waves over a broad range of periods have been matched simultaneously in both waveform and amplitude by synthetic seismograms using a single source model that is consistent with geologic and geodetic data (e.g., Heaton, 1982).

\section{EARThQUake Data SeTS}

The source parameters of the earthquakes used in the construction of scaling relations are given in Table 1 . The earthquakes are grouped into three regional categories: eastern North America; other continental interiors; and western North America.

Eastern North American earthquakes. The set of eastern North American earthquakes presented here includes all main shock events whose seismic moments and source durations could be estimated from the modeling of body waves. The locations and focal mechanisms of the events, with the exception of the Baffin Bay event, are shown in Figure 2. The set includes four events that occurred before the establishment of the WWSSN in the early 1960's. The source parameters of these events were obtained from body wave and surface wave analyses by Ebel et al. (1986) using teleseismic recordings from mechanical and electromagnetic seismographs. The remaining earthquakes occurred in the period from 1963 to 1983 , for which data from the WWSSN and other networks are available. The largest of these events is the $m_{b} 5.9$ Baffin Bay earthquake of 1963. Most of the events 


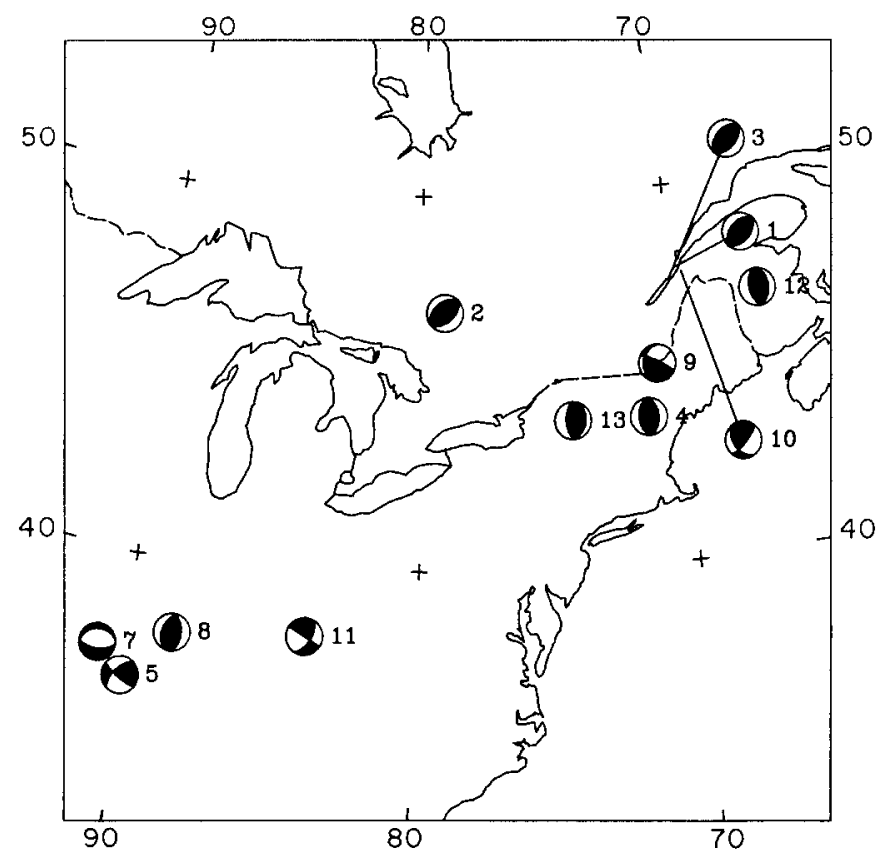

FIG. 2. Focal mechanism solutions of eastern North American earthquakes. The shaded regions represent compression in a lower hemisphere projection. Earthquakes are identified by numbers in Table 1 .

occurred in the northeastern United States and adjoining regions of Canada. These include the 1973 Maine, 1979 Charlevoix, 1982 New Brunswick, and 1983 New York events. The remaining events are the 1963 and 1965 Missouri, the 1968 Illinois, and the 1980 Kentucky earthquakes. For some of the events, source parameters had been estimated by other investigators, notably the nodal plane solution and surface wave seismic moment estimates of Herrmann (1979) and Herrmann et al. (1982) for the 1963 and 1965 Missouri, 1968 Illinois, 1973 Maine, and 1980 Kentucky earthquakes.

Since most of the eastern North American events that were studied are small $\left(m_{b L_{g}}<5\right)$, a large number of data sources were accessed, and the compilation of data for each event was made as complete as possible. Particular emphasis was placed on obtaining short-period teleseismic $P$-wave recordings from instruments having broader responses than that of the WWSSN, in order to obtain better resolution of the source durations of the smaller events. These additional data sources include the LRSM stations, the Canadian Seismograph Network, and the Yellowknife, Canada, and Eskdalemuir, Scotland arrays.

Earthquakes from other continental interiors. Based on the expectation that earthquakes in the interiors of continents share some common source characteristics, source parameters for a set of earthquakes from other continental interiors were compiled from the published literature in order to augment the set of eastern North American earthquakes, particularly for larger magnitudes. However, in recognition of the differences in tectonic environment between eastern North America and other continental interiors, these two sets were analyzed separately, and the combined data set was used for the purpose of comparison with the eastern North American data set. The seismic moments of these events were estimated from surface waves or long-period body waves, and their source durations were 
estimated from long-period body waves. To augment published studies, the source parameters of three events that were thought to be especially pertinent for comparison with eastern North America because of their locations in stable continental environments were obtained in this study. These events are the 1969 Ceres, South Africa, the 1979 Cadoux, Western Australia, and the 1983 Guinea earthquakes.

Earthquakes in Western North America. To provide a comparison of source scaling between eastern and western North America, source parameters for a set of western North American earthquakes were compiled from the published literature. This set includes all main shock events whose seismic moments and source durations have been estimated from the modeling of body waves. The moments of the 23 events range from $6.2 \times 10^{22}$ to $2.0 \times 10^{26}$ dyne-cm. While the predominant faulting mechanism of the events is strike-slip, there are several reverse and normal faulting events in the data set. The source parameters of the smaller events were obtained by the modeling of regional body waves, including strong motion recordings in some cases. For the larger events, the source parameters were obtained from both regional and teleseismic records, providing strong constraints on the source parameters.

\section{Estimation of Seismic Moment}

Seismic moment estimates obtained by a wide variety of methods were used in this study. These include the use of surface waves at regional and teleseismic distances, the use of long-period and broadband body waves at regional, upper mantle, and teleseismic distances, and the use of short-period body waves at closein and teleseismic distances.

Long-period body waves contain a great deal of information about the overall size and average source processes of an earthquake, and seismic moment and source mechanism may be readily determined by teleseismic body wave modeling. However, earthquakes in the magnitude range $5<m_{b}<6$ often are not well-recorded teleseismically, and recordings at distances of less than about $30^{\circ}$ provide the only long-period body wave data available for analysis. Where teleseismic $P$-wave modeling usually requires consideration of only three rays, direct $P$ and the surface reflections $p P$ and $s P$, waveform modeling at less than $30^{\circ}$ requires summation of many more arrivals. In the following sections, the use of $P_{n l}$ waves and upper mantle body waves for the estimation of seismic moment is described and illustrated using the 9 November 1968 Illinois earthquake. A complete description of the analysis of this and other events is given by Somerville (1986).

Estimation of seismic moment using $P_{n l}$ waves. At distances of less than about $15^{\circ}$, the seismogram is dominated by waves traveling in the crustal wave guide. In terms of rays, the wave train includes rays that have undergone multiple reflections within the crust, including mode conversions at the free surface and at the Mohorovičic discontinuity. The initial part of the record is dominated by $P$ headwaves $\left(P_{n}\right)$ and the later part of the record includes more $S V$ energy $(P L)$. We refer to the entire wave train before the $S$-wave time as $P_{n l}$. At the longer periods, the amplitude and waveform of $P_{n l}$ is relatively insensitive to details of crustal structure but is quite sensitive to the source orientation of the event. The method of computing synthetic seismograms and estimating moment has been described in detail by Helmberger and Engen (1980) and Wallace et al. (1981a).

The $P$-wave first motions of the central Illinois earthquake of 9 November 1968 were used by Stauder and Nuttli (1970) to obtain a focal mechanism with a strike of $195^{\circ}$, a dip of $45^{\circ}$, and a rake of $102^{\circ}$. A study of surface wave spectral amplitudes 
TABLE 1

EARTHQUaKe SoUrCe Parameters

\begin{tabular}{|c|c|c|c|c|c|c|c|c|c|c|c|c|c|c|c|c|}
\hline No. & Region & Date & Time & Latitude & Longitude & $S^{*}$ & $\begin{array}{c}\text { Depth } \\
(\mathrm{km})\end{array}$ & $S^{*}$ & $m_{b L g}$ & $M_{0}$ & $\mathrm{SDF}^{* *}$ & $S^{*}$ & $\begin{array}{l}\text { Duration } \\
\text { (sec) }\end{array}$ & $\mathrm{SDF}^{* *}$ & $S^{*}$ & $\begin{array}{l}\text { Stress } \\
\text { Drop } \\
\text { (bars) }\end{array}$ \\
\hline \multicolumn{17}{|c|}{ Eastern North America } \\
\hline 1 & Charlevoix & $1925 / 3 / 1$ & $2: 19: 15.0$ & $47.80 \mathrm{~N}$ & $69.80 \mathrm{~W}$ & $\mathrm{~S} 80$ & 10.0 & ES85 & 6.6 & $0.22 \mathrm{E}+27$ & 4.0 & - & 5.0 & 1.2 & ES85 & 300 \\
\hline 2 & Timiskaming & $1935 / 11 / 1$ & $6: 03: 34.0$ & $46.90 \mathrm{~N}$ & $79.10 \mathrm{~W}$ & DG84 & 10.0 & ES85 & 6.2 & $0.51 \mathrm{E}+26$ & 1.7 & - & 5.0 & 1.2 & ES85 & 80 \\
\hline 3 & Charlevoix & $1939 / 10 / 19$ & $11: 53: 54.0$ & $48.00 \mathrm{~N}$ & $69.70 \mathrm{~W}$ & S80 & 8.0 & - & 5.6 & $0.10 \mathrm{E}+25$ & 5.0 & - & 1.5 & 1.3 & - & 60 \\
\hline 4 & Ossippee & $1940 / 12 / 20$ & $7: 27: 26.0$ & $43.90 \mathrm{~N}$ & $71.40 \mathrm{~W}$ & DG84 & 10.0 & ES85 & 5.5 & $0.12 \mathrm{E}+25$ & 5.0 & - & 0.8 & 1.3 & ES85 & 400 \\
\hline 5 & Missouri & $1963 / 3 / 3$ & $17: 30: 11.4$ & $36.70 \mathrm{~N}$ & $90.10 \mathrm{~W}$ & $\mathrm{H} 79$ & 15.0 & H79 & 4.7 & $0.11 E+24$ & $1.5 \dagger$ & H79 & 0.5 & 1.5 & - & 200 \\
\hline 6 & Baffin Bay & $1963 / 9 / 4$ & $13: 32: 08.0$ & $71.30 \mathrm{~N}$ & $73.00 \mathrm{~W}$ & LK80 & 7.0 & LK80 & & $0.16 \mathbf{E}+26$ & 2.1 & - & 3.0 & 1.4 & LK80 & 100 \\
\hline 7 & Missouri & $1965 / 10 / 21$ & $2: 04: 38.5$ & $37.50 \mathrm{~N}$ & $91.00 \mathrm{~W}$ & H79 & 4.0 & - & 4.8 & $0.90 \mathrm{E}+23$ & $1.5 \dagger$ & H79 & 0.5 & 1.2 & - & 100 \\
\hline 8 & Illinois & $1968 / 11 / 9$ & 17:01:41.1 & $38.00 \mathrm{~N}$ & $88.50 \mathrm{~W}$ & H79 & 25.0 & - & 5.5 & $0.13 E+25$ & 1.5 & - & 0.7 & 1.7 & - & 400 \\
\hline 9 & Maine & $1973 / 6 / 15$ & 1:09:04.2 & $45.30 \mathrm{~N}$ & $70.90 \mathrm{~W}$ & H79 & 6.0 & - & 5.0 & $0.62 \mathrm{E}+23$ & $1.5 \dagger$ & $\mathrm{H} 79$ & 0.8 & 1.6 & - & 20 \\
\hline 10 & Quebec & $1979 / 8 / 19$ & $22: 49: 31.0$ & $47.67 \mathrm{~N}$ & $69.60 \mathrm{~W}$ & HW80 & 6.5 & - & 5.0 & $0.15 \mathrm{E}+24$ & 1.5 & HW80 & 0.9 & 1.3 & - & 30 \\
\hline 11 & Kentucky & $1980 / 7 / 27$ & $18: 52: 21.8$ & $38.18 \mathrm{~N}$ & $83.94 \mathrm{~W}$ & $\mathrm{MC} 82$ & 13.5 & - & 5.2 & $0.48 \mathrm{E}+24$ & 1.9 & - & 1.1 & 1.2 & - & 50 \\
\hline 12 & New Brunswick & $1982 / 1 / 9$ & $12: 53: 51.7$ & $46.98 \mathrm{~N}$ & $66.66 \mathrm{~W}$ & N84 & 7.0 & N84 & 5.8 & $0.13 \mathrm{E}+25$ & 1.5 & - & 0.8 & 1.3 & N84 & 500 \\
\hline 13 & New York & $1983 / 10 / 7$ & $10: 18: 46.1$ & $43.94 \mathrm{~N}$ & $74.26 \mathrm{~W}$ & TP85 & 7.0 & TP85 & 5.2 & $0.25 \mathrm{E}+24$ & $1.5 \dagger$ & SS84 & 0.6 & $1.5 \dagger$ & TP85 & 200 \\
\hline \multicolumn{17}{|c|}{ Continental Interiors } \\
\hline 1 & Koyna & $1967 / 12 / 10$ & $22: 51: 24.3$ & $17.38 \mathrm{~N}$ & $73.75 \mathrm{E}$ & NG68 & 4.4 & L76 & & $0.32 \mathbf{E}+26$ & 1.4 & L76 & 6.4 & 1.2 & L76 & 20 \\
\hline 2 & Ceres & $1969 / 9 / 29$ & $20: 02: 32.1$ & $33.16 \mathrm{~S}$ & $19.31 \mathrm{E}$ & NB86 & 11.0 & - & & $0.45 \mathrm{E}+26$ & 1.4 & - & 5.0 & 1.2 & NB86 & 70 \\
\hline 3 & Lake McKay & $1970 / 3 / 24$ & $10: 35: 12.9$ & $21.90 \mathrm{~N}$ & $126.60 \mathrm{E}$ & LK80 & 12.0 & LK80 & & $0.11 \mathrm{E}+26$ & $1.6 \dagger$ & LK80 & 2.5 & 1.4 & LK80 & 100 \\
\hline 4 & Gazli & $1976 / 4 / 8$ & $2: 40: 23.9$ & $40.31 \mathrm{~N}$ & $63.72 \mathrm{E}$ & KB80 & 10.0 & KB80 & & $0.29 \mathrm{E}+27$ & 1.9 & - & 5.0 & 1.2 & KB80 & 400 \\
\hline 5 & Friuli & $1976 / 5 / 6$ & $20: 00: 12.5$ & $46.35 \mathrm{~N}$ & $13.26 \mathrm{~W}$ & ISC & 8.0 & EN85 & & $0.39 \mathrm{E}+26$ & 1.9 & - & 4.5 & $1.2 \dagger$ & $\mathrm{C} 80$ & 80 \\
\hline 6 & Gazli & $1976 / 5 / 17$ & $2: 58: 41.1$ & $40.35 \mathrm{~N}$ & $63.45 \mathrm{E}$ & KB80 & 15.0 & KB80 & & $0.19 E+27$ & 1.6 & - & 7.5 & 1.1 & H80 & 80 \\
\hline 7 & Tangshan & $1976 / 7 / 27$ & $19: 42: 54.6$ & $39.60 \mathrm{~N}$ & $118.00 \mathrm{E}$ & USGS & 10.0 & BS79 & & $0.40 \mathrm{E}+27$ & 1.3 & BS79 & 8.7 & 1.1 & BS79 & 100 \\
\hline 8 & Tabas & $1978 / 9 / 16$ & $15: 35: 56.6$ & $33.39 \mathrm{~N}$ & $57.43 \mathrm{E}$ & NK81 & 10.0 & NK81 & & $0.13 E+28$ & 1.7 & - & 12.0 & $1.1 \dagger$ & NK80 & 100 \\
\hline 9 & Cadoux & $1979 / 6 / 2$ & $9: 47: 58.7$ & $30.83 \mathrm{~S}$ & $117.18 \mathrm{E}$ & DA86 & 6.0 & DA86 & & $0.75 \mathrm{E}+25$ & 1.3 & DA86 & 2.0 & 1.4 & DA86 & 200 \\
\hline 10 & Guinea & $1983 / 12 / 22$ & $4: 11: 29.2$ & $11.87 \mathrm{~N}$ & $13.53 \mathrm{~W}$ & USGS & 13.0 & - & & $0.21 \mathrm{E}+26$ & 1.9 & - & 5.0 & 1.2 & DD84 & 30 \\
\hline 11 & Gazli & $1984 / 3 / 19$ & $20: 28: 38.3$ & $40.30 \mathrm{~N}$ & $63.30 \mathrm{E}$ & EN85 & 10.0 & EN85 & & $0.25 \mathrm{E}+27$ & 1.5 & - & 12.0 & 1.1 & EN85 & 30 \\
\hline \multicolumn{17}{|c|}{ Western North America } \\
\hline 1 & Long Beach & 1933/11/1 & 1:54:07.8 & $33.62 \mathrm{~N}$ & $117.97 \mathrm{~W}$ & CIT & 10.0 & WC79 & & $0.62 \mathrm{E}+26$ & 1.5 & WC79 & 6.5 & 1.3 & WC79 & 40 \\
\hline 2 & El Golfo & $1966 / 8 / 7$ & $17: 36: 22.8$ & $31.72 \mathrm{~N}$ & $114.42 \mathrm{~W}$ & B77 & 10.0 & EB78 & & $0.57 \mathrm{E}+26$ & 1.2 & EB78 & 4.0 & 1.3 & EB78 & 200 \\
\hline
\end{tabular}




\begin{tabular}{|c|c|c|c|c|c|c|c|c|c|c|c|c|c|c|}
\hline Truckee & $1966 / 9 / 12$ & $16: 41: 02.6$ & $39.44 \mathrm{~N}$ & $120.16 \mathrm{~W}$ & S70 & 10.0 & EB78 & $0.11 E+26$ & 1.9 & EB78 & 3.0 & $1.4 \dagger$ & EB78 & 80 \\
\hline Borrego Mountain & $1968 / 4 / 9$ & $2: 28: 59.1$ & $33.19 \mathrm{~N}$ & $116.12 \mathrm{~W}$ & BM75 & 8.0 & BM76 & $0.18 \mathrm{E}+27$. & 1.7 & EB78 & 5.0 & $1.2 \dagger$ & BM76 & 300 \\
\hline Harris Ranch & $1969 / 10 / 27$ & 10:59:42.8 & $36.79 \mathrm{~N}$ & $121.39 \mathrm{~W}$ & JM74 & 12.5 & JM74 & $0.42 \mathrm{E}+24$ & 1.5 & JM74 & 0.7 & 1.4 & JM74 & 300 \\
\hline Hollister & $1970 / 3 / 13$ & $7: 02: 28.6$ & $36.86 \mathrm{~N}$ & $121.42 \mathrm{~W}$ & JM74 & 10.2 & JM74 & $0.71 \mathrm{E}+23$ & 2.1 & JM74 & 0.5 & 1.4 & JM74 & 100 \\
\hline San Fernando & $1971 / 2 / 9$ & $14: 00: 41.8$ & $34.44 \mathrm{~N}$ & $118.41 \mathrm{~W}$ & $\mathrm{H} 82$ & 13.0 & $\mathrm{~L} 78$ & $0.86 \mathrm{E}+26$ & 2.0 & L78 & 6.0 & $1.2 \dagger$ & L78 & 70 \\
\hline Limekiln Road & $1971 / 12 / 29$ & $0: 25: 35.7$ & $36.69 \mathrm{~N}$ & $121.34 \mathrm{~W}$ & JM74 & 3.7 & JM74 & $0.16 \mathrm{E}+23$ & $2.0 \dagger$ & HJ77 & 0.4 & 1.4 & HJ77 & 30 \\
\hline Melendy Ranch & $1972 / 2 / 24$ & $15: 56: 51.3$ & $36.59 \mathrm{~N}$ & $121.20 \mathrm{~W}$ & JM74 & 6.4 & JM74 & $0.31 \mathrm{E}+24$ & 1.7 & HJ77 & 0.9 & 1.4 & HJ77 & 80 \\
\hline Stone Canyon & $1972 / 9 / 4$ & $18: 04: 40.9$ & $36.64 \mathrm{~N}$ & $121.26 \mathrm{~W}$ & JM74 & 5.1 & JM74 & $0.89 \mathrm{E}+23$ & $2.0 \dagger$ & HJ77 & 0.9 & 1.4 & HJ77 & 20 \\
\hline San Juan Bautista & $1972 / 10 / 3$ & $6: 30: 02.0$ & $36.80 \mathrm{~N}$ & $121.53 \mathrm{~W}$ & JM74 & 5.2 & JM74 & $0.72 \mathrm{E}+23$ & 2.2 & JM74 & 0.7 & 1.4 & JM74 & 50 \\
\hline Point Mugu & $1973 / 2 / 21$ & $14: 45: 57.2$ & $34.10 \mathrm{~N}$ & $119.04 \mathrm{~W}$ & SE76 & 14.0 & SE76 & $0.27 \mathrm{E}+25$ & 1.8 & BS76 & 1.5 & 1.2 & BS76 & 200 \\
\hline Morgan Hill & $1973 / 10 / 3$ & $10: 07: 27.4$ & $37.20 \mathrm{~N}$ & $121.60 \mathrm{~W}$ & BRK & 6.0 & HM75 & $0.21 \mathrm{E}+23$ & $2.0^{\dagger}$ & HM75 & 0.8 & 1.5 & HM75 & 8 \\
\hline Oroville & $1975 / 8 / 1$ & $20: 20: 12.9$ & $39.44 \mathrm{~N}$ & $121.53 W$ & MS76 & 5.5 & LB76 & $0.10 \mathrm{E}+26$ & 1.8 & LB76 & 3.0 & 1.4 & LB76 & 70 \\
\hline Brawley & $1976 / 11 / 4$ & 10:41:37.6 & $33.08 \mathrm{~N}$ & $115.60 \mathrm{~W}$ & $\mathrm{HH} 78$ & 7.0 & HH78 & $0.32 \mathrm{E}+24$ & $1.5 \dagger$ & HH76 & 1.5 & 1.4 & HH78 & 20 \\
\hline Santa Barbara & $1978 / 8 / 13$ & $22: 54: 52.4$ & $34.40 \mathrm{~N}$ & $119.68 \mathrm{~W}$ & WH81 & 12.0 & WH81 & $0.11 \mathrm{E}+26$ & $1.5 \dagger$ & WH81 & 6.0 & 1.2 & WH81 & 10 \\
\hline Coyote Lake & $1979 / 8 / 6$ & $17: 05: 22.7$ & $37.10 \mathrm{~N}$ & $121.50 \mathrm{~W}$ & BRK & 8.0 & LH83 & $0.35 \mathrm{E}+25$ & $1.2 \dagger$ & LH83 & 2.0 & 1.5 & LH83 & 80 \\
\hline Anza & $1980 / 2 / 25$ & $10: 47: 38.7$ & $33.52 \mathrm{~N}$ & $116.55 \mathrm{~W}$ & PAS & 13.6 & F84 & $0.56 \mathrm{E}+24$ & 1.5 & F84 & 0.5 & 1.2 & F84 & 700 \\
\hline Mammoth & $1980 / 5 / 25$ & $16: 33: 44.9$ & $37.61 \mathrm{~N}$ & $118.85 \mathrm{~W}$ & BL83 & 9.0 & BL83 & $0.19 \mathrm{E}+26$ & 1.5 & BL83 & 7.0 & 1.2 & BL83 & 10 \\
\hline Mammoth & $1980 / 5 / 27$ & $14: 50: 57.3$ & $37.51 \mathrm{~N}$ & $118.83 W$ & BL83 & 14.0 & BL83 & $0.10 \mathrm{E}+26$ & 1.5 & BL83 & 2.0 & 1.2 & BL83 & 200 \\
\hline Anza & $1982 / 6 / 15$ & $23: 49: 21.3$ & $33.56 \mathrm{~N}$ & $116.67 \mathrm{~W}$ & F84 & 12.2 & F84 & $0.23 \mathrm{E}+24$ & 1.3 & F84 & 0.4 & 1.2 & F84 & 500 \\
\hline Coalinga & $1983 / 5 / 2$ & $23: 42: 37.8$ & $36.23 \mathrm{~N}$ & $120.29 W$ & E84 & 12.0 & HH83 & $0.45 \mathrm{E}+26$ & 1.2 & K84 & 5.0 & 1.2 & HH83 & 70 \\
\hline
\end{tabular}

* $\mathrm{S}=$ source of preceding values, keyed to references as follows-letter(s): author(s) surname initial(s); number: year this century; - : source is this study (see also Somerville, 1986).

** SDF = standard deviation factor of preceding value.

$\uparrow$ SDF was estimated from a single measurement. 
supports this mechanism and gives $M_{0}=9.0 \times 10^{24}$ dyne-cm for a focal depth of 22 km (Herrmann, 1979).

Only two stations, OXF (delta $=396 \mathrm{~km}$, azimuth $\left.=192^{\circ}\right)$ and BLA $($ delta $=719$ $\mathrm{km}$, azimuth $=95^{\circ}$ ), provided usable records of $P_{n 1}$ waveforms. The observed and synthetic waveforms, both filtered to remove the higher frequency motions that are not modeled well by the simple crustal structure used, are shown in Figure 3. The synthetic waveforms were calculated from Green's functions for a source at a depth of $8 \mathrm{~km}$ in a layer-over-half-space crustal structure. The crustal parameters are $V_{p}$ $=6.2 \mathrm{~km} / \mathrm{sec}, V_{s}=3.5 \mathrm{~km} / \mathrm{sec}$, density $=2.7 \mathrm{gm} / \mathrm{cm}^{3}$, thickness $=32 \mathrm{~km}$, and the mantle parameters are $V_{p}=8.2 \mathrm{~km} / \mathrm{sec}, V_{s}=4.5 \mathrm{~km} / \mathrm{sec}$, and density $=3.4 \mathrm{gm} /$ $\mathrm{cm}^{3}$. These parameters are a reasonable approximation of focal depth and crustal thickness for all of the other events studied, but the Illinois earthquake occurred at a depth of $22 \mathrm{~km}$ in a somewhat thicker crust (Herrmann, 1979). However, as discussed by Helmberger and Engen (1980) and Wallace (1983), the effect of increased source depth and crustal thickness is quite similar to the effect of distance. These effects could therefore be compensated for by using Green's functions calculated for a range increased by about $100 \mathrm{~km}$. This does not significantly affect the estimate of seismic moment.

The match of the synthetic seismograms to the data is good for BLA, and

\section{ILLINOIS $\quad 9$ Nov. 1968}

OXF
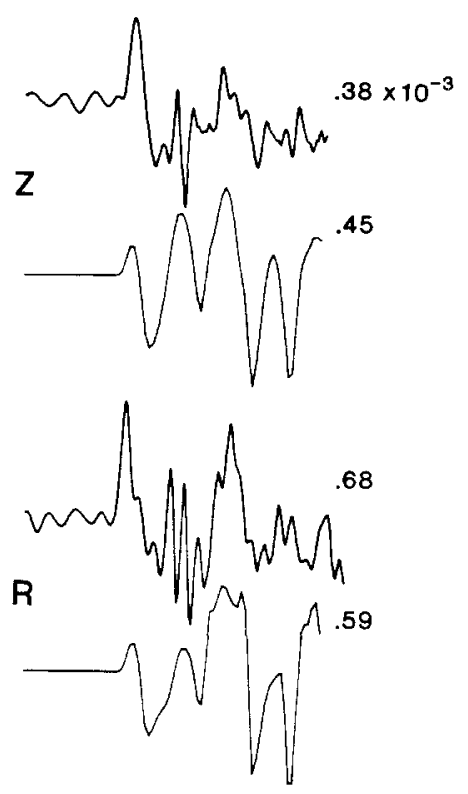

BLA
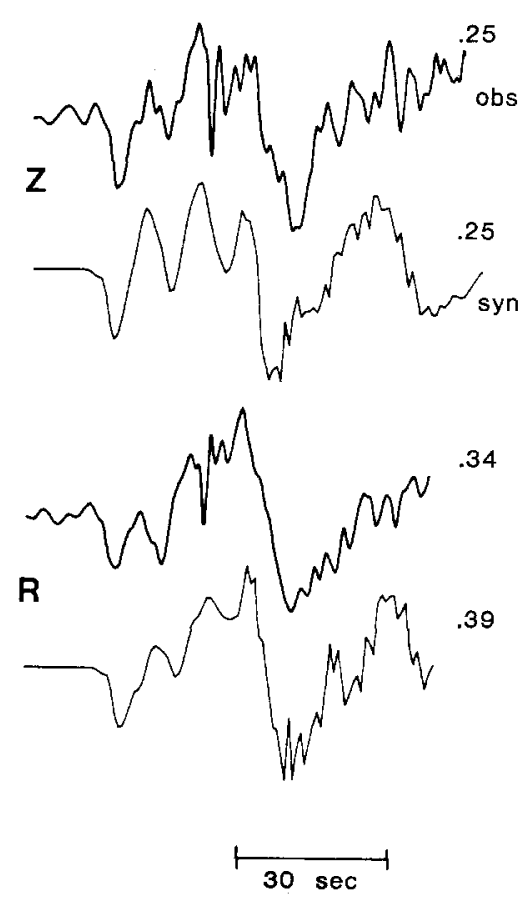

FIG. 3. Observed (upper trace) and synthetic (lower trace) $P_{n l}$ waveforms for the 9 November 1968 Illinois earthquake for the vertical $(Z)$ and radial $(R)$ components. Peak-to-peak amplitudes are given in $\mathrm{cm} \times 10^{-3}$. Synthetic amplitudes represent the average moment of $1.3 \times 10^{24}$ dyne-cm determined from these records. 
somewhat less good for $\mathrm{OXF}$, which is at a smaller distance and more affected by the variations in structure. The seismic moment obtained is $1.3 \times 10^{24}$ dyne-cm, which is about 50 per cent greater than the surface wave estimate of Herrmann (1979).

Estimation of seismic moment using upper mantle body waves. At distances of $15^{\circ}$ to $30^{\circ}$, the seismogram is dominated by rays that have bottomed within the upper mantle. Although multiple reflections are not necessary to match these waveforms, a large number of rays bottoming at various depths in the upper mantle must be included. The presence of discontinuities in the upper mantle may create several arrivals at a given distance.

Three records of the Illinois earthquake of 9 November 1968 were available for using long-period $P$ waves within the upper mantle triplication range: DUG (delta $\left.=19.0^{\circ}\right)$; TUC $\left(\right.$ delta $\left.=19.1^{\circ}\right)$; and GSC $\left(\right.$ delta $\left.=22.8^{\circ}\right)$. Synthetic seismograms were generated using the upper mantle model T7 (Burdick and Helmberger, 1978) derived for paths from the Western to the Central United States, which is the reverse of the paths for these records. Synthetic seismograms computed for this model are shown in Figure 4 together with the data. The comparison of observed amplitudes with those obtained using the $\mathrm{T} 7$ model yielded a seismic moment of $1.8 \times 10^{24}$ dyne-cm, which is twice the surface wave estimate of Herrmann (1979). These two moment estimates are not inconsistent when the uncertainties of each estimate are taken into account.

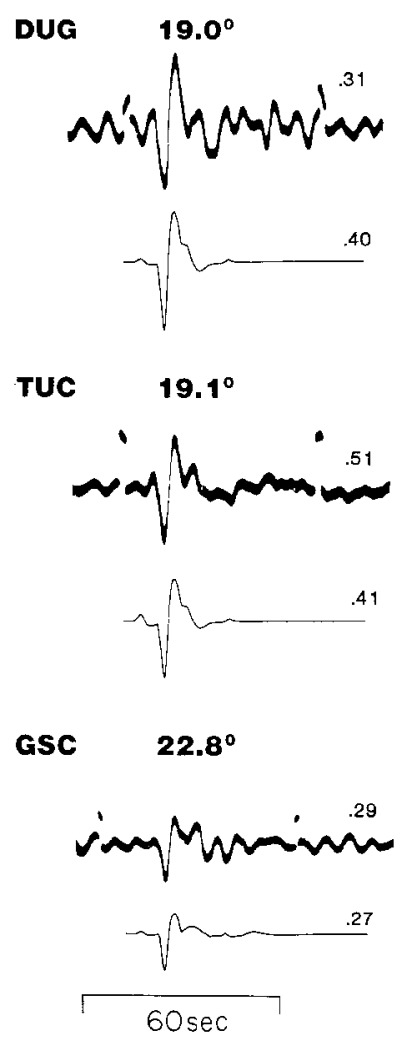

FIG. 4. Observed (upper trace) and synthetic (lower trace) upper mantle waveforms for the 9 November 1968 Illinois earthquake. Peak-to-peak amplitudes in $\mathrm{cm} \times 10^{-3}$ are shown. Synthetic amplitudes represent the average moment of $1.8 \times 10^{24}$ dyne-cm determined from these records using the T7 structure model. 


\section{Estimation of Source Duration}

Estimates of source duration were obtained from teleseismic long-period or shortperiod body waves or, for the smaller Western United States events, from near-in broadband recordings. The source durations were estimated from the overall durations of simple triangular or trapezoidal source functions that provided the best fit to the observed seismograms. While this procedure may be satisfactory for simple sources, it leads to ambiguity in cases of asperities on a single fault plane (such as the 1968 Borrego Mountain earthquake) and ruptures on multiple planes (such as the 1976 Tangshan earthquake). In these cases, our method may only measure a part of the duration of the entire event and thereby give a result that more closely represents the asperity or one component of a multiple rupture.

For events with durations of a few seconds or more, estimates obtained from long-period teleseismic body waves were used. The resolution of approximately 1 sec that is obtainable from the WWSSN long-period instrument determined the lower bound on uncertainty in these duration estimates. Consequently, the fractional uncertainties of the shorter durations are substantially larger than those of the longer durations.

Estimation of source duration using short-period $P$ waves. For events with duration estimates of less than a few seconds, durations were estimated from shortperiod teleseismic body waves. The method of Langston and Helmberger (1975) was used for modeling shallow dislocation sources at distances of $30^{\circ}$ to $90^{\circ}$ to avoid upper mantle triplications and the core shadow zone. The source function was represented by a triangular pulse having equal rise and fall times.

Anelastic absorption is by far the most important contributor to uncertainty in the estimation of the source duration of earthquakes using short-period teleseismic $P$ waves. The amount of absorption and its frequency dependence are subjects upon which there exists considerable difference of opinion. The simplest assumption is that of frequency-independent $Q$, in which case the effect of absorption can be described by the single parameter $t^{*}$ (Futterman, 1962) which represents the cumulative effect of absorption along the raypath. In this study, $t^{*}$ was assumed to be 0.5 for all of the paths between the eastern North American events and their teleseismic recording stations. This value is consistent with published estimates for short-period $P$ waves (Der and Lees, 1985; Burger et al., 1987b) and produced synthetic amplitudes that were generally consistent with the amplitudes of the observed short-period waves. Since absorption and source duration jointly contribute to the duration of the observed waveforms, departures from the assumed average value of $t^{*}$ are a source of potential bias and scatter in the source duration estimates obtained in this study. The resolution of source duration decreases significantly for source durations less than about $0.5 \mathrm{sec}$ because the contribution of absorption to the duration of the waveform becomes dominant in this case.

The fit between the observed and synthetic seismograms was measured using a waveform norm. This norm consists of the cross-correlation (Burdick, 1977) between the first three half-cycles of the two signals. This norm is more sensitive to zero crossings than to other aspects of the waveform and so is well suited to the measurement of duration.

The estimation of source duration is illustrated using the 1968 Illinois earthquake as an example. The observed waveforms for this event and the synthetic waveforms calculated for the estimated source duration of $0.7 \mathrm{sec}$ are shown in Figure 5. The variation of the waveform norm of individual stations as a function of source 

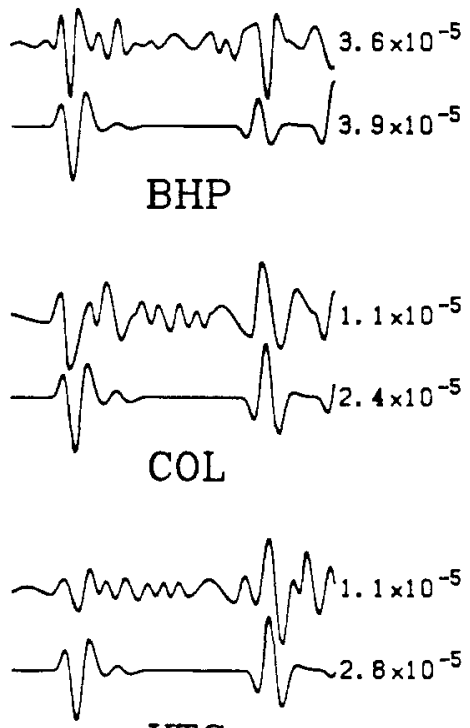

KTG

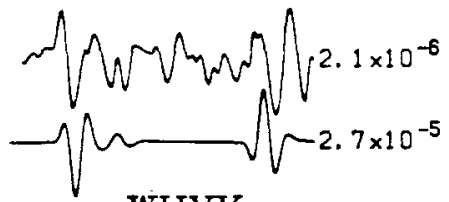

WHYK

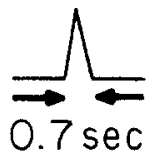

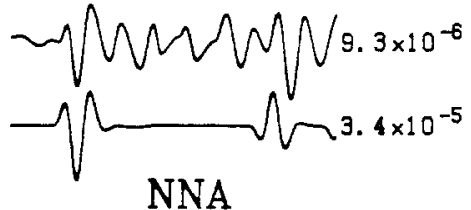

NNA

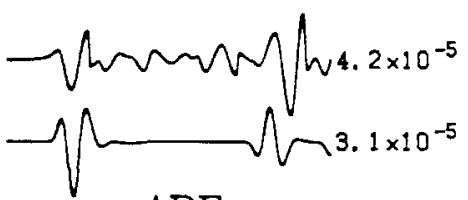

ARE

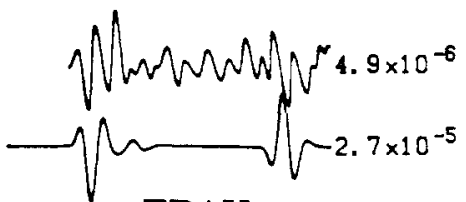

FBAK

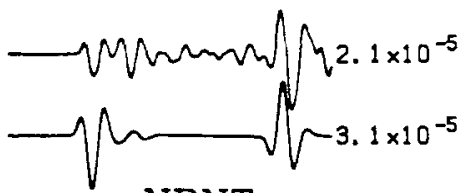

NPNT

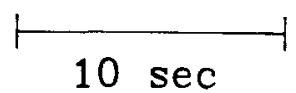

\section{Source Function}

Fig. 5. Observed (upper trace) and synthetic (lower trace) short-period teleseismic $P$ waveforms of the 9 November 1968 Illinois earthquake. Peak amplitudes are shown in centimeters.

duration is shown in Figure 6. The uncertainty in source duration of this event, represented by a standard deviation factor of 1.7 , was the largest of all of the events analyzed. The method of estimating the source duration of the event and its uncertainty from the individual station measurements is described in the following section.

\section{RePresentation of Uncertainty in Moment and Duration Estimates}

Uncertainties in seismic moment and source duration of each event were expressed separately as geometric standard deviation factors about their medians. Thus, the values separated from the median by one standard deviation are given by the product and ratio of the median with this standard deviation factor. This method of representing the uncertainty accomplishes two useful functions. First, it allows the expression of uncertainties exceeding a factor of 2 which exist in some estimates and which cannot be represented by additive standard deviations. Second, when fitting a least-squares line to the logarithms of seismic moment and source duration, the standard deviation uncertainty factors become (additive) standard 


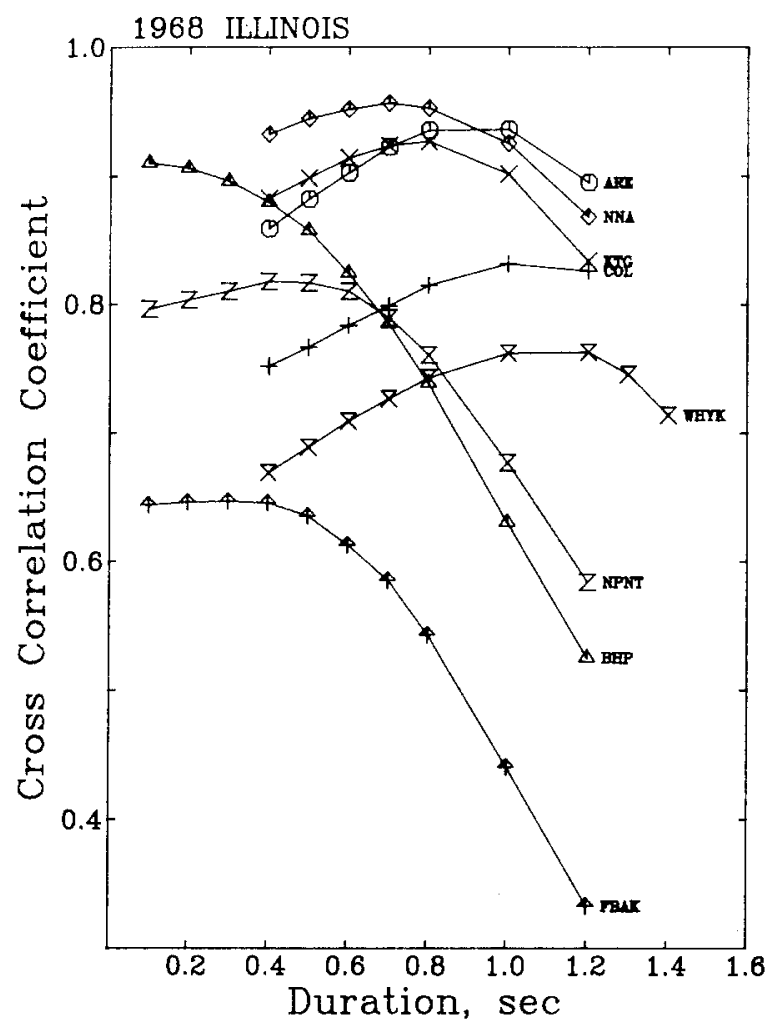

FIG. 6. Waveform cross-correlation coefficient as a function of source duration for each station recording the 1968 Illinois earthquake.

deviations about the mean, and are therefore convenient for the analysis of uncertainty in the scaling relations.

It was assumed that measurements of seismic moment and source duration at individual stations were lognormally distributed about the median values, and inspection of these distributions showed that they were not inconsistent with this assumption. Accordingly, the values were represented by the weighted means and standard deviations of the logarithms of the individual measurements. For seismic moment, low weights were assigned to nodal observations, while for source duration, low weights were assigned to poorly resolved and poorly correlated maxima in crosscorrelation.

When estimates of seismic moment were available from more than one study, they were combined using the following procedure. Assuming the estimates to be lognormally distributed, the combined estimate was obtained from the weighted mean of the logarithms of the estimates, with the weights being inversely proportional to the variances of estimates. The standard deviation of the mean was obtained from its variance, which was estimated by adding the variance of the estimates about their mean to the average variance of the estimates. This procedure requires the assumption that the number of observations used in obtaining the estimates is the same for all studies, which is considered to be a reasonable approximation for the events analyzed.

The estimates of seismic moment and source duration values and standard deviation factors estimated using the methods described above are listed in Table 1. The use of geometrical standard deviation factors to describe uncertainties implies 
that, for a set of events, the values of one parameter corresponding to a fixed value of the other parameter are lognormally distributed. Analysis of the distributions of seismic moment and source duration values indicated that they are not inconsistent with lognormal distributions.

\section{SCALing Relations}

The source scaling relation [equation (4)] for each regional category was obtained by fitting a least-squares straight line to the logarithm of the measured moment and duration values. The fitting was done using the method of York (1966) which, besides taking account of errors in both quantities, allows the specification of different error estimates for each data point. This is an important property for this study because of the wide range of error estimates for the measured values. These error estimates are used to obtain weights that determine the relative importance of the contribution of each data point to the least-squares fit.

Plots of seismic moment against source duration for eastern North America, other continental interiors, and western North America are shown in Figures 7, 8, and 9, respectively. The combined eastern North American and other continental interior events are shown in Figure 10. The error estimates for each measurement are shown in order to indicate the weights given to each point and do not imply that they otherwise constrain the least-squares fit. Also shown are scaling relations

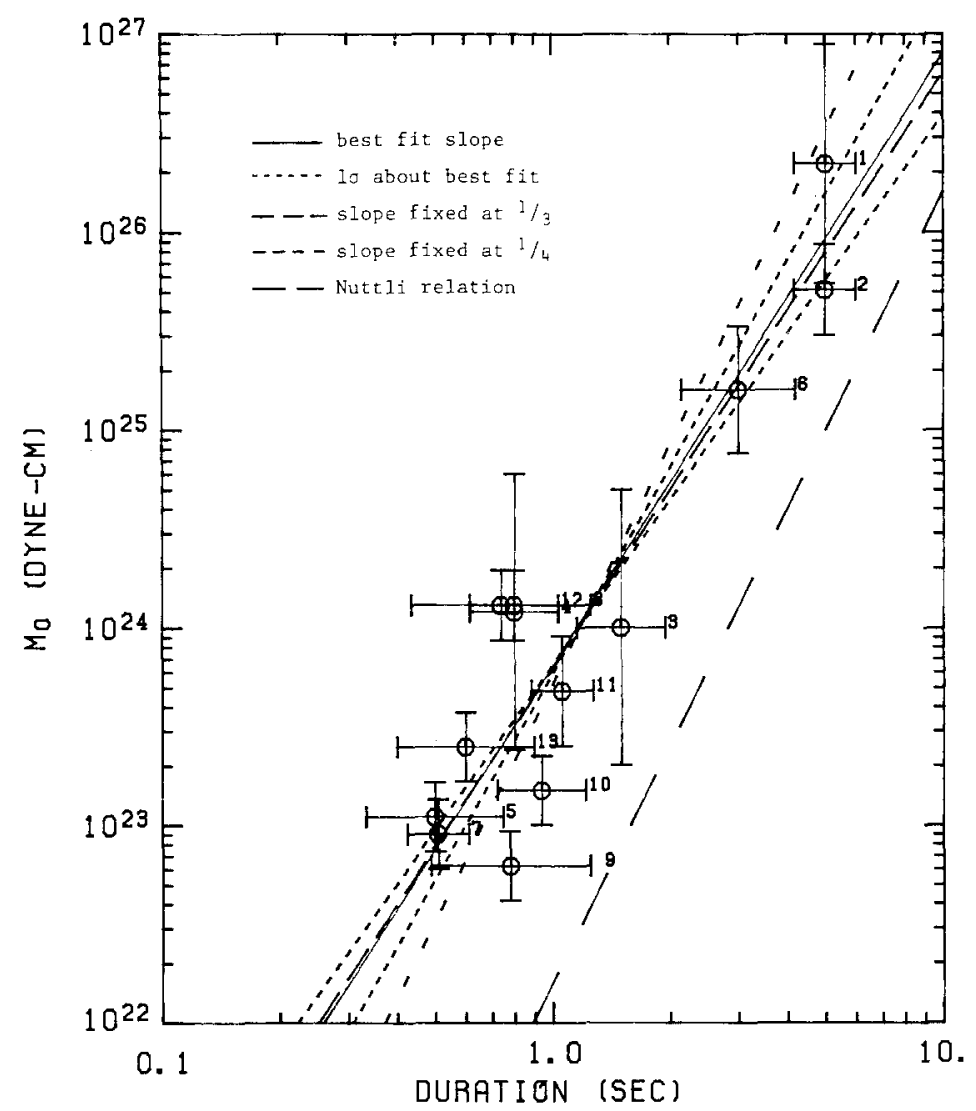

FIG. 7. Source scaling relation for eastern North America. The median values and standard deviation factors of seismic moment and source duration, coded by event number, are plotted in the figure and listed in Table 1, and the scaling relations are described in Table 2. 


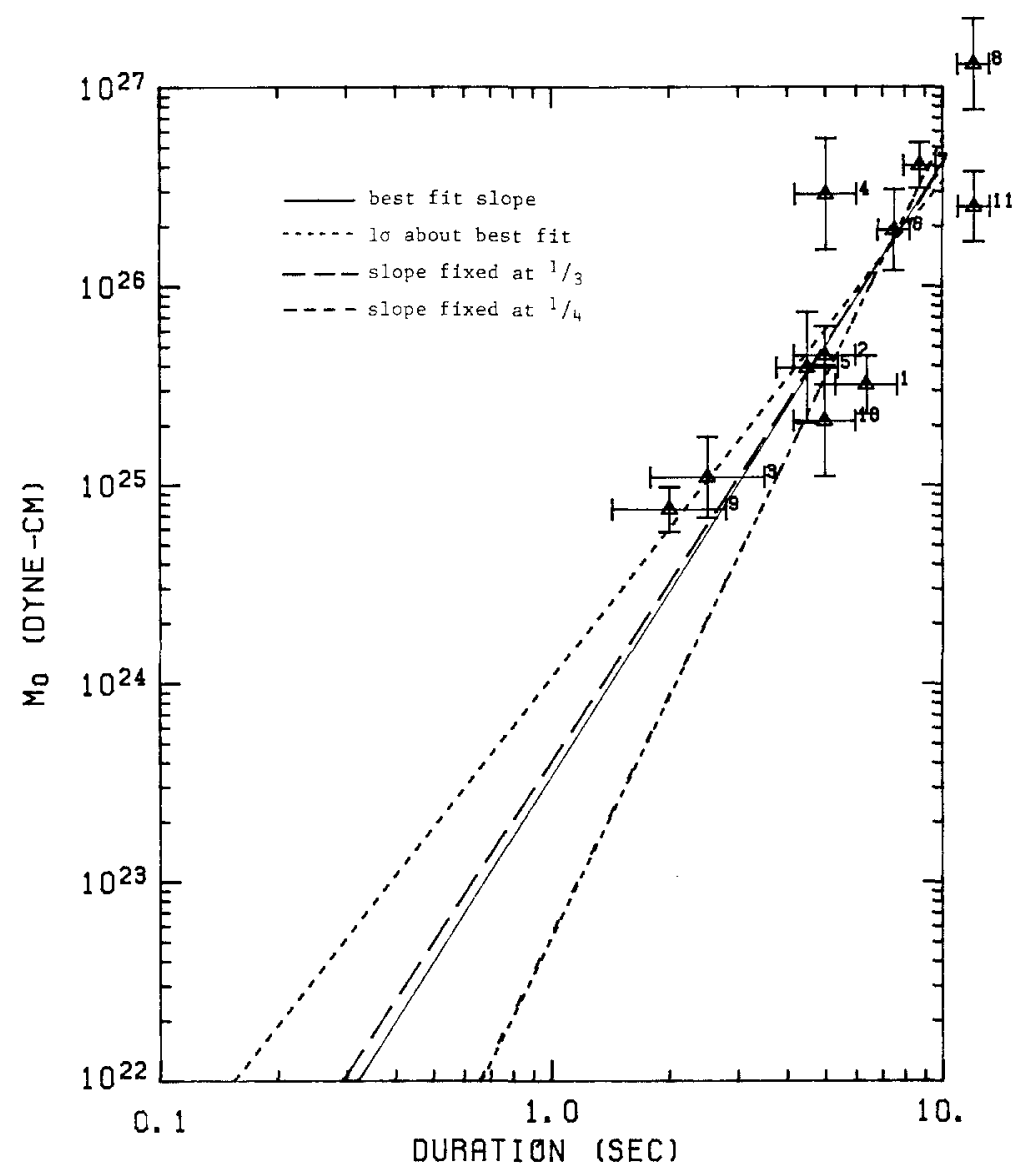

FIG. 8. Source scaling relation for other continental interiors. See Figure 7 legend for explanation.

showing the best-fit line, lines of one standard deviation in slope, and lines of slopes 3 and 4 for reference. All of the data points are plotted together in Figure 11, with lines of constant stress drop. The scaling relations are summarized in Table 2, together with scaling relations constrained to have a slope of 3 (constant stress drop), and Nuttli's (1983b) scaling relation with a slope of 4 . The estimated slopes and their standard deviations are shown graphically in Figure 12.

Goodness of fit of the measurements to the scaling relations. It is important to first consider how well each set of measurements is fit by a single straight line representing its scaling relation. The goodness of fit is a function (in log space) of the moment and duration residuals about the line and of the uncertainties in the moment and duration estimates. The latter are applied as (inverse) weights to the former to obtain the weighted sum of the squares of the residuals [York, 1966, equation (7)], which is the quantity that is minimized in the fitting procedure. This sum of squares, which is listed in Table 2, is normalized such that its value will equal the number of degrees of freedom (two less than the number of points) if the points just fit the line within the measurement error.

For eastern North America, the sum of squares is less than the number of degrees of freedom, indicating that the scaling relation fits the points better than would have been expected on the basis of the errors of the measurements. However, for other continental interiors and for western North America, the sums of squares are 


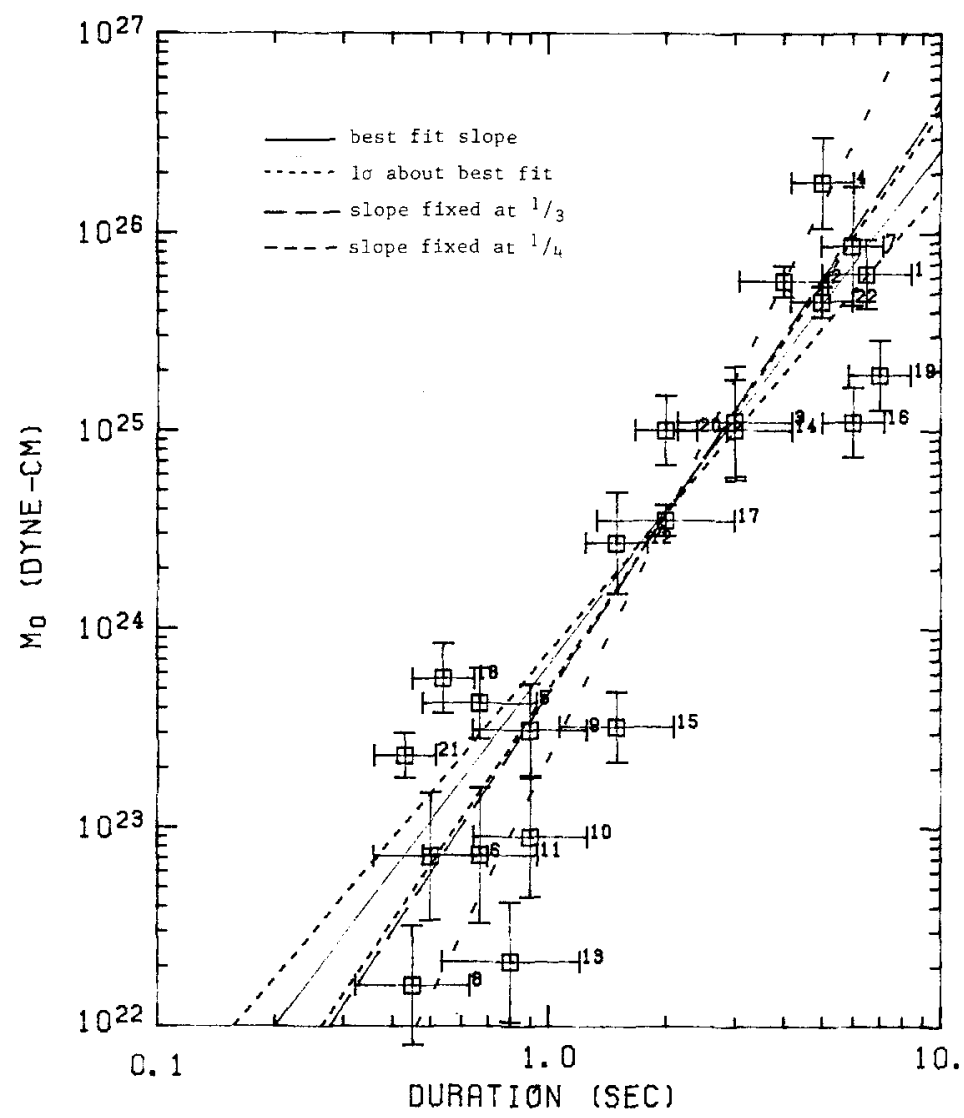

Fig. 9. Source scaling relation for western North America. See Figure 7 legend for explanation.

larger than the number of degrees of freedom, indicating that either the measurement error has been underestimated or the points do not fit the straight line. The sum of squares as defined by York (1966) follows the $\chi^{2}$ distribution, permitting a test of the significance of these differences. For eastern North America, the difference between the sum of squares and the number of degrees of freedom is not significant. For other continental interiors, the difference is somewhat significant, falling just below the 95 per cent confidence level. When the eastern North American and other continental interior events are combined, their sum of squares is close to the number of degrees of freedom, indicating that the difference is insignificant. However, for western North America, the difference is significant at the 99.5 per cent confidence level. It is concluded that individual events in western North America show significant departures from a single source scaling relation, while for eastern North America and other continental interiors, individual events are consistent with a single relation.

We have not attempted to fit scaling relations having more complex forms, as these do not appear to be required by the data. The apparent lower bound of about $0.5 \mathrm{sec}$ in source duration, which might suggest that duration does not decrease as moment decreases below about $10^{24}$ dyne-cm, is more likely due to the inability of our method of duration estimation to resolve durations less than $0.5 \mathrm{sec}$. Our study is directed to earthquakes of engineering interest (with moments above about $10^{24}$ dyne-cm) and does not address the source scaling relations of smaller earthquakes. 


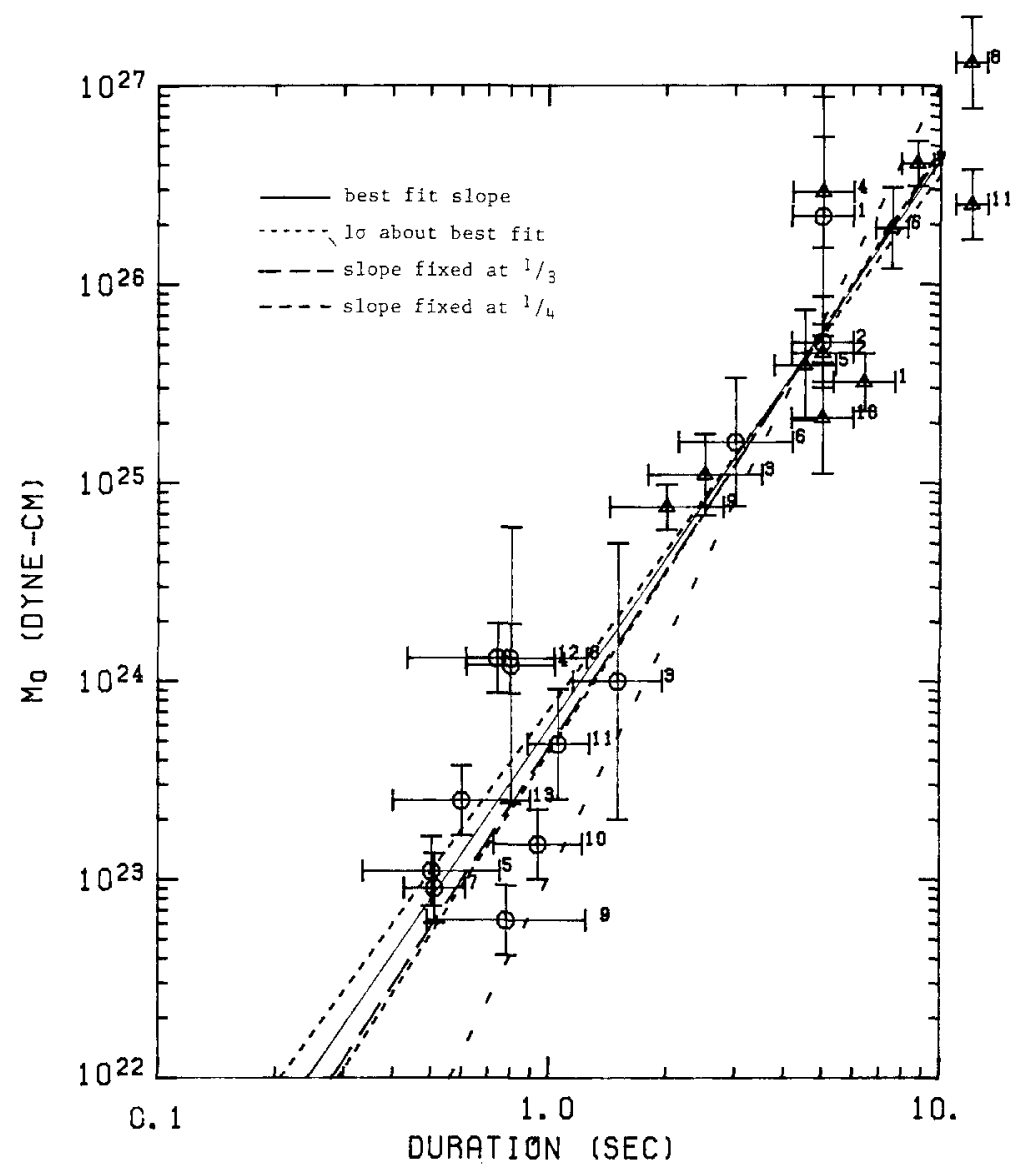

FIG. 10. Source scaling relation for eastern North America and other continental interiors. See Figure 7 legend for explanation.

Comparison of slopes of scaling relations in different regions. The slopes of the scaling relations for the different regions are summarized in Table 2 and Figure 12. The values of the slopes of the relations are compared with the values of 3 , representing constant stress drop, and 4, representing the value proposed by Nuttli (1983b). The significance of differences in slope are expressed using the following terms. Values falling within one standard deviation (a confidence interval of 68 per cent) are described as somewhat inconsistent, and values falling outside two standard deviations (a confidence interval of 95 per cent) are described as very inconsistent. The selected terminology expresses the belief that the uncertainties in slope obtained from the least-squares fitting represent a lower bound on uncertainty. This is because the slope is sensitive to changes in the values of critical data points in a way that is not adequately represented by the weights assigned on the basis of uncertainty estimates. The scaling relation for eastern North America is particularly subject to this effect because of the small number of data points for the larger seismic moments.

The slope of 3.09 in the scaling relation for eastern North America is consistent with a slope of 3 and very inconsistent with a slope of 4 . The slope of the relation for other continental interior events is the same as that for eastern North America and is also consistent with a value of 3 . However, the slope has large uncertainty 


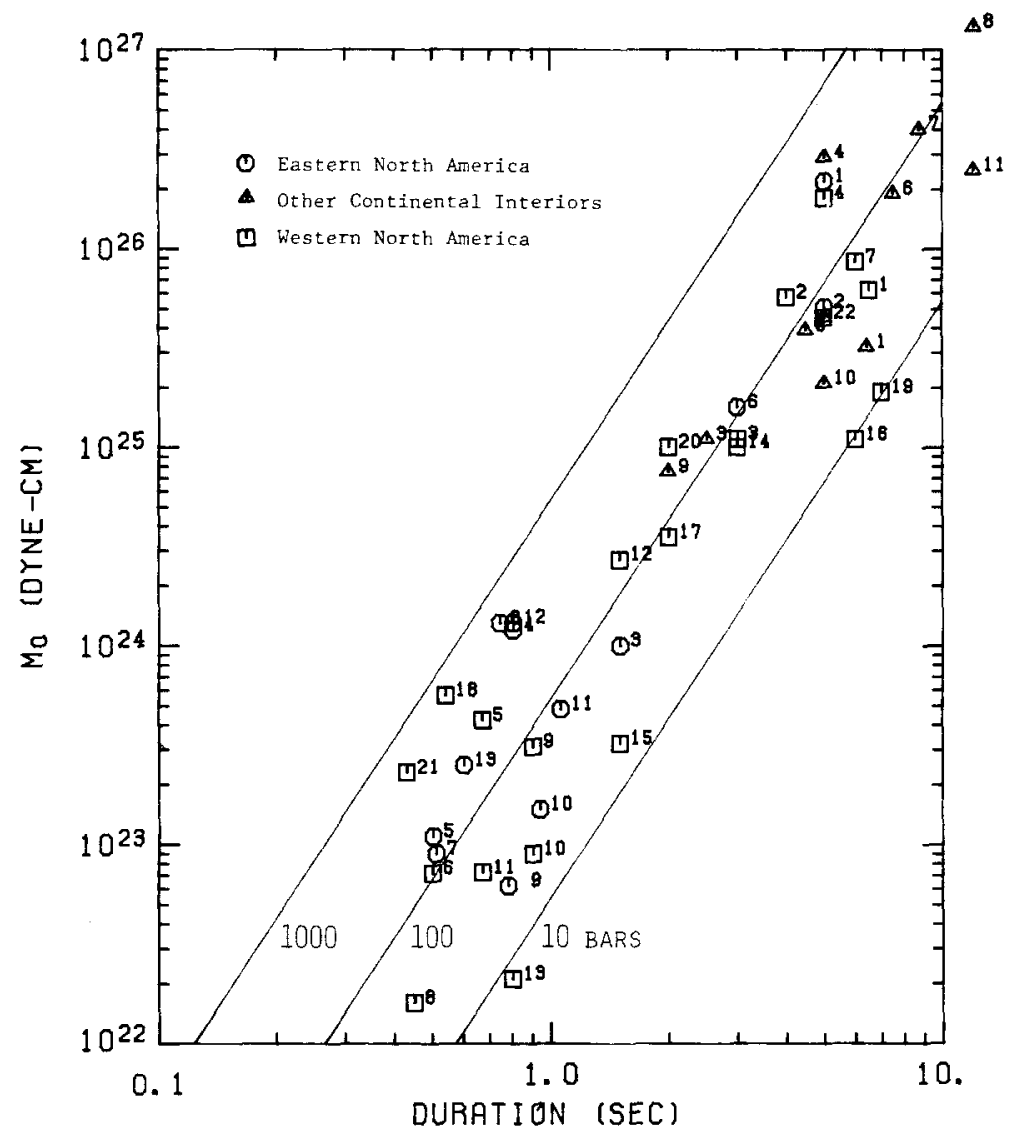

FIG. 11. Seismic moments and source durations of earthquakes from eastern North America, other continental interiors, and western North America. Lines of constant stress drop obtained using the relation of Cohn et al. (1982) are shown.

due to the narrow range of seismic moments spanned by the measurements and is at the margin of being somewhat inconsistent with a slope of 4 .

In order to place stronger constraint on the slope of the scaling relation, the eastern North American events are combined with the events from other continental interiors. When this is done, the resulting slope is decreased to approximately 2.85 . This value is consistent with a value of 3 but very inconsistent with a value of 4 .

The decrease in slope above the values for the individual populations occurs because the eastern events have larger stress drops than the other continental interior events. This suggests that it may not be appropriate to combine these two data sets. An analysis of the difference in stress drops between the two populations, which is given below, indicates that the difference is not statistically significant. Nevertheless, the comparison between the populations that is afforded by the available measurements is rather limited because there is little overlap in the ranges of seismic moment spanned by the two populations. This suggests caution in the use of the combined population.

The slope of the scaling relation for western North America was found to be 2.6, which is somewhat inconsistent with the value of 3 but very inconsistent with the value of 4 . The uncertainty in the slope for western North America is also much larger than that for the combined eastern North American and other continental 
TABLE 2

SCALING RELATIONS:

$\log _{10}($ Moment $)=$ Intercept + Slope $\times \log _{10}($ Duration $)$

\begin{tabular}{lclccccc}
\hline \multicolumn{1}{c}{ Region $^{*}$} & Intercept & Slope† & $\begin{array}{c}\text { Slope } \\
\text { Standard } \\
\text { Deviation }\end{array}$ & $\begin{array}{c}\text { Degrees of } \\
\text { Freedom }\end{array}$ & Sums¥ $\begin{array}{c}\text { Stress } \\
\text { Drop }\end{array}$ \\
\hline ENAM & 23.81 & 3.09 & 0.34 & 11 & 8.7 & \\
& 23.80 & 3 & & & & 120 \\
CINT & 23.53 & 3.09 & 0.72 & 9 & 16.2 & \\
& 23.61 & 3 & & & & 75 \\
ENAM and CINT & 23.77 & 2.85 & 0.17 & 22 & 25.8 & \\
& 23.66 & 3 & & & & 85 \\
WNAM & 23.80 & 2.60 & 0.29 & 20 & 48.8 & \\
& 23.67 & 3 & & & & 90 \\
ENAM, CINT & 22.20 & 4 & & 11 & 109.4 & \\
(Nuttli, 1983b) & & & & & & \\
\hline
\end{tabular}

* ENAM = eastern North America; CINT = other continental interiors; and WNAM $=$ western North America.

$\dagger$ Upper values = slope unconstrained; lower values = slope constrained to 3 (constant stress drop).

$\ddagger$ Weighted sum of squares of residuals.

interior events. (Although the uncertainty in slope is a function of the size of the data set used, this comparison of uncertainties is appropriate since the two data sets are nearly equal in size.) The scaling relation for western North America was also found to be a poor fit to the measurements, suggesting that these events have quite heterogeneous source characteristics. This may reflect the variability in fault strength and stress regime near a plate margin. In particular, the faults are known to have widely different slip rates, which would imply different static stress drops according to the model of Kanamori and Allen (1986). Thus, for the purposes of comparison of source characteristics, it may not be appropriate to combine these events into a single set. However, in applications to strong ground motion evaluation, it has been customary to combine events from western North America into a single set. This practice has been justified because the differences in ground motion between different kinds of events have not been clearly established, although they may exist. The combination of the western events in this study rests on a similar justification.

Comparison of stress drop in different regions. The source characteristics of earthquakes in the three regions are most conveniently compared using stress drop as a means of describing the relation of seismic moment to source duration. Uncertainties in the estimation and interpretation of stress drop have already been discussed, and include limitations in the model used to calculate stress drop, uncertainties in the seismic moment and source duration values used in the calculation, and ambiguities in the definition of stress drop of events having complex ruptures.

The scaling relations for eastern North America, other continental interiors, and the combination of these two sets are consistent with constant stress drop, whereas the western North American events are somewhat inconsistent. However, in order to facilitate the comparison, it is simplest to assume constant stress drop so that each population can be represented by a single average stress drop value.

The mean and standard deviations of the stress drops of the three populations 


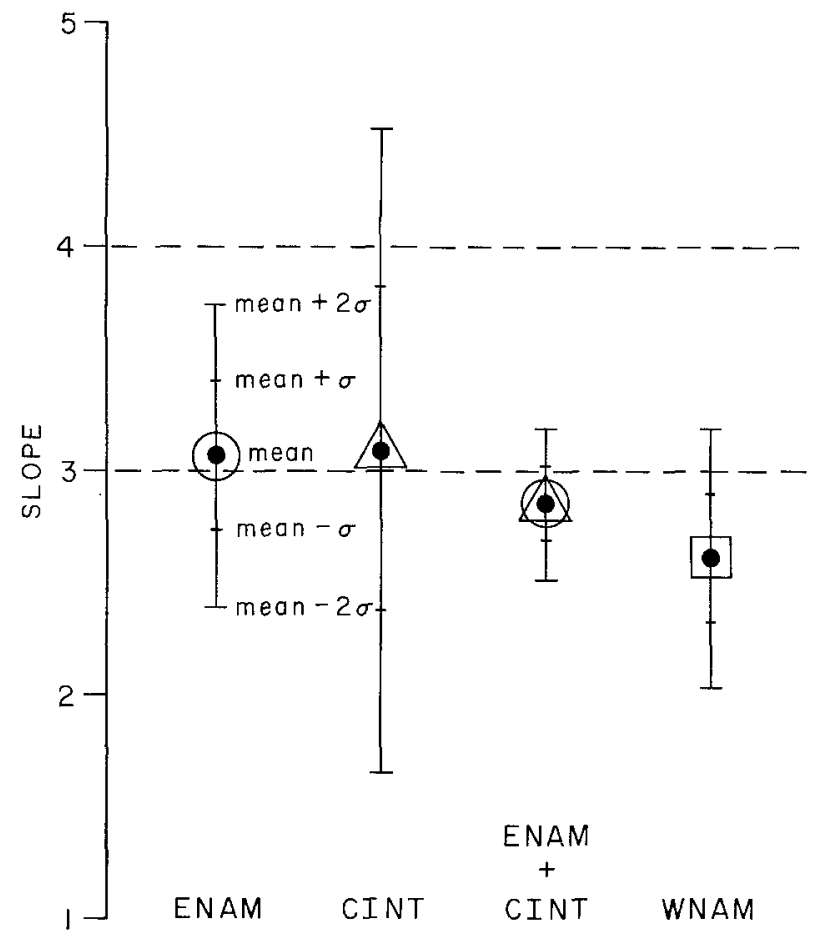

FIG. 12. Means and standard deviations of slopes of the scaling relations. ENAM, CINT, and WNAM represent eastern North America, other continental interiors, and western North America, respectively.

are listed in Table 2 and illustrated in Figure 13. The eastern, western and other continental interior events have average stress drops of 120,90, and 75 bars, respectively. The average stress drop of the eastern events is a factor of 1.3 greater than that of the western events and 1.6 greater than the other continental interior events.

The significance of the differences in average constant stress drop are tested using the Student's $t$ distribution. At a confidence level of 95 per cent, the uncertainty in the difference in stress drop between east and west is a factor of 2.3, and between eastern North America and other continental interiors is a factor of 2.2. These uncertainties are much greater than the differences in average stress drop noted above. It is concluded that the differences in average stress drop between the various regional categories are not significant and that the average stress drops of all of the regional categories are quite consistent with a value of 100 bars.

Comparison of source characteristics of eastern and western North American earthquakes. In the preceding analysis, the source scaling characteristics of eastern and western North American earthquakes have been shown to be broadly similar. However, two principal differences in the source properties of eastern and western North American earthquakes were noted. These are the greater variability of source characteristics of the western events and the tendency of their stress drops to decrease slightly with seismic moment. By comparison, earthquakes in eastern North America have more uniform source characteristics and show constant stress drop scaling.

The uniformity in source properties of eastern events may be explained by the model of Kanamori and Allen (1986) which relates static stress drop to average 


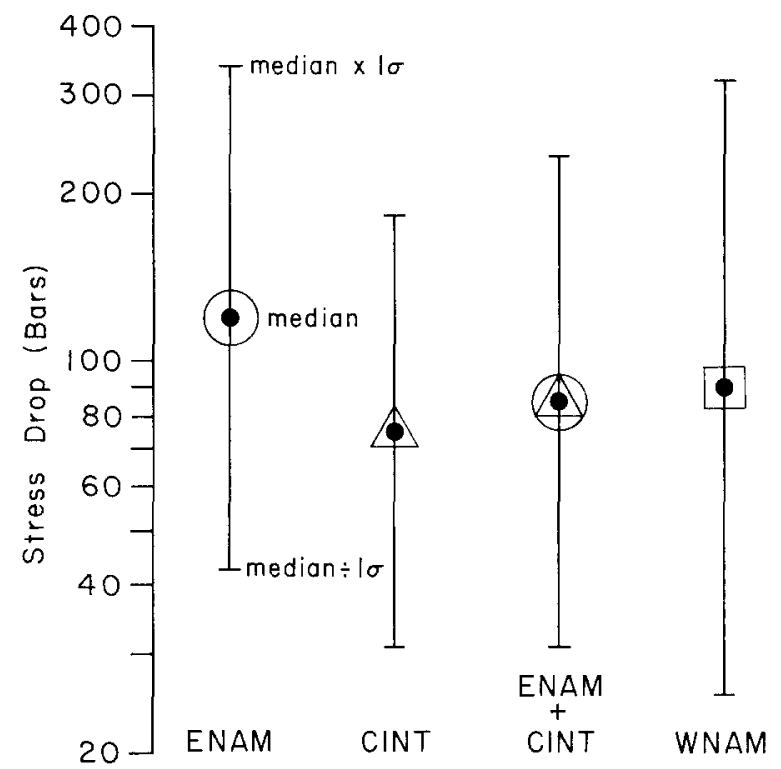

FIG. 13. Median values and standard deviation factors of stress drops assuming constant stress drop scaling relations. ENAM, CINT, and WNAM represent eastern North America, other continental interiors, and western North America, respectively.

repeat time. They suggest that earthquakes in eastern North America have very long repeat times and expect their stress drops to be high. According to this model, the relative uniformity in stress drops of eastern events may be due to their uniformity in repeat time.

Kanamori and Allen (1986) demonstrated that the static stress drops of western North American events span a wide range and that they show a tendency to increase with earthquake repeat time in accordance with their model. This wide variation in repeat times is presumably responsible for the wide range in stress drops of western events that was also found in the present study. This variability indicates that it is inappropriate to group western events into a single category for the purpose of evaluating source characteristics. However, as has already been noted, western events are commonly grouped together for the purpose of evaluating strong ground motion characteristics. When this is done, the median stress drop of the western events is found to be not significantly different from that of the eastern events. While it may be true, as Kanamori and Allen (1986) state, that a factor of 5 difference in average stress drop is commonly seen between earthquakes with short and long repeat times, this difference is not observed between the median values for western and eastern North American earthquakes.

The observation that the stress drops of western North American events decrease slightly with increasing moment may be explained by an asperity model as follows. The smaller events (or at least the high stress drop smaller events) may be generated largely by the breaking of an asperity. As the earthquake size increases, a decreasing proportion of the fault surface that ruptures consists of asperities. This would reduce the seismic moment in comparison with that from the rupture of a large asperity.

The difference in slope of the scaling relations between eastern and western North America may be explained by the model in the following way. For the smaller events, the eastern and western events have similar stress drops. Thus, both 
populations of smaller events may reflect a comparable upper limit in shear strength. As fault size increases, the rupture zones in the east may still be mostly asperities, resulting in a constant stress drop. The large proportion of asperities in eastern fault zones may be due to their longer repeat times and their consequent greater roughness, as suggested by the model of Kanamori and Allen (1986). In the west, the decreasing proportion of asperities with increasing earthquake size results in slightly decreasing stress drop on average. However, the rupture zones of some large western events may also be largely composed of asperities or one big asperity. In this case, the stress drop will be close to the stress drops of the smaller events and to the stress drops of large eastern events. Thus, the eastern and western events may share the same upper bound on stress drop, which is an approximately constant stress drop relation.

\section{IMPLiCATIONS FOR Strong Ground Motion Estimation}

We have found that the stress drops of eastern North American and western North American earthquakes are not significantly different on average. This result is constrained by seismograms whose frequency content does not extend very far above the corner frequency. Projection of this result to the higher frequencies of engineering interest using simple spectral models suggests that those aspects of strong ground motion amplitudes that are attributable to the earthquake source may also not be significantly different between eastern and western North America.

The source scaling relation for eastern North American earthquakes is expressed in a form that renders it directly applicable to the estimation of strong ground motions using random vibration models (Hanks and McGuire, 1981; Boore, 1983; Atkinson, 1984; Boore and Atkinson, 1987). In these models, the source is represented by a segment of band-limited noise whose amplitude is scaled by the seismic moment. The lower frequency cutoff of the spectral band is defined by the Brune (1970) corner frequency, which is proportional to the inverse of the source duration estimated in this study (Cohn et al., 1982).

The source parameters of eastern North American earthquakes have been used in this study only to construct source scaling relations. However, these parameters can also be used to evaluate a broad range of issues relating to earthquake sources, strong ground motion characteristics, and seismic hazard analysis in the Eastern United States. For example, the focal depths of large eastern North American earthquakes, estimated with an accuracy of a few kilometers using depth phases, appear to be largely confined to the upper crust. The stress drops of individual events, having standard deviation factors of 5 on average and listed in Table 1 to one significant figure, do not show any significant regional variation or depth dependence. The seismic moment estimates obtained in this study provide valuable information for the construction of an empirical relation between seismic moment and $m_{b L g}$ (Burger et al., 1987a, this volume) for use in seismic hazard analyses in the Eastern United States.

\section{CONCLUSIONS}

Source scaling relations have been constructed for earthquakes in eastern North America and other continental interiors, and compared with a relation constructed for earthquakes in western North America. Detailed analysis of the uncertainties in the scaling relations has allowed the resolution of two important issues concerning the source scaling of earthquakes in eastern North America. First, the source characteristics of earthquakes in eastern North America and other continental 
interiors are consistent with constant stress drop scaling and are inconsistent with nonconstant scaling models, such as that of Nuttli (1983b). Second, the stress drops of earthquakes in eastern North America and other continental interiors are not significantly different from those of earthquakes in western North America and have median values of approximately 100 bars. The principal differences in the source properties of eastern and western North American earthquakes are the greater variability of the source characteristics of the western events, and the tendency of their stress drops to decrease slightly with seismic moment.

\section{ACKNOWLEDGMENTS}

The authors are greatly indebted to several individuals who provided seismograms for analysis in this study. Dr. Alan Douglas and Peter Marshall of the United Kingdom Atomic Energy Authority provided digital seismograms from the UKAEA array stations. Robert Halliday and William Shannon loaned film seismograms and provided copies of seismograms from the Canadian Seismograph Network. Barbara Rubin of Teledyne-Geotech provided digital seismograms from the LRSM and SDCS Networks. Dr. Derek York provided a copy of his least-squares fitting program, and Dr. Ram Kulkarni provided guidance in the statistical analyses. A stimulating review of the work was provided by Dr. Jeffrey Barker. This study was sponsored by the Electric Power Research Institute. The research topic was suggested by Dr. J. Carl Stepp, and the research program was managed by Dr. Jerry King.

\section{REFERENCES}

Aki, K. (1967). Scaling law of seismic spectrum, J. Geophys. Res. 72, 1217-1231.

Atkinson, G. M. (1984). Attenuation of strong ground motion in Canada from a random vibration approach, Bull. Seism. Soc. Am. 74, 2629-2653.

Barker, J. S. and C. A. Langston (1983). A teleseismic body-wave analysis of the May 1980 Mammoth Lakes, California, earthquakes, Bull. Seism. Soc. Am. 73, 419-434.

Barker, J. S. and C. A. Langston (1986). The effect of local structure on moments and corner frequencies (submitted for publication).

Boore, D. M. (1983). Stochastic simulation of high-frequency ground motions based on seismological models of the radiated spectra, Bull. Seism. Soc. Am. 73, 1865-1894.

Boore, D. M. and D. J. Stierman (1973). Source parameters of the Pt. Mugu, California, earthquake of February 21, 1973, Bull. Seism. Soc. Am. 66, 385-404.

Boore, D. M. and G. M. Atkinson (1986). Stochastic prediction of ground motion and spectral response parameters at hard-rock sites in eastern North America, Bull. Seism. Soc. Am. 77, 440-467.

Brune, J. N. (1970). Tectonic stress and the spectra of seismic shear waves from earthquakes, J. Geophys. Res. 75, 4997-5009.

Burdick, L. J. (1977). Broad-band seismic studies of body waves, Ph.D. Thesis, California Institute of Technology, Pasadena, California, $151 \mathrm{pp}$.

Burdick, L. J. and G. R. Mellman (1976). Inversion of body waves from the Borrego Mountain earthquake to the source mechanism, Bull. Seism. Soc. Am. 66, 1485-1499.

Burdick, L. J. and D. V. Helmberger (1978). The upper mantle $P$ velocity structure of the western United States, J. Geophys. Res. 83, 1699-1712.

Burger, R. W., P. G. Somerville, J. S. Barker, R. B. Herrmann, and D. V. Helmberger (1987a). The effect of crustal structure on strong ground motion attenuation relations in eastern North America, Bull. Seism. Soc. Am. 77, 420-439.

Burger, R. W., T. Lay, and L. J. Burdick (1987b). Average $Q$ and yield estimates from the Pahute Mesa test site, Bull. Seism. Soc. Am. 77 (in press).

Butler, R., G. S. Stewart, and H. Kanamori (1979). The July 27, 1976 Tangshan, China earthquake-A complex series of intraplate events, Bull. Seism. Soc. Am. 69, 207-220.

Cipar, J. (1981). Teleseismic observations of the 1976 Friuli earthquake sequence, Bull. Seism. Soc. Am. 70, 963-983.

Cohn, S. N., T. L. Hong, and D. V. Helmberger (1982). The Oroville earthquakes: a study of source characteristics and site effects, $J$. Geophys. Res. 87, 4585-4594.

Denham, D., L. G. Alexander, I. B. Everingham, P. J. Gregson, T. C. Wallace, and J. Enever (1986). Intraplate stress and the 1979 Cadoux earthquake (submitted for publication).

Der, Z. A. and A. C. Lees (1985). Methodologies for estimating $t^{*}(f)$ from short-period body waves and regional variations in $t^{*}(f)$ in the United States, Geophys. J. R. Astr. Soc. 82, 125-140. 
Dorbath, C., L. Dorbath, R. Gaulon, T. George, P. Mourge, M. Ramdani, B. Robineau, and B. Tadili (1984). Seismotectonics of the Guinean earthquake of December 22, 1983, Geophys. Res. Letters 11, 971-974.

Ebel, J. E., L. J. Burdick, and G. S. Stewart (1978). The source mechanism of the August 7, $1966 \mathrm{El}$ Golfo earthquake, Bull. Seism. Soc. Am. 68, 1281-1292.

Ebel, J. E., P. G. Somerville, and J. D. Mclver (1986). A study of the source parameters of some large earthquakes of northeastern North America, J. Geophys. Res. 91, 8231-8247.

Eyidoğan, H., J. Näbělek, and M. N. Toksöz (1985). The Gazli, USSR, 19 March 1984 earthquake: the mechanism and tectonic implications, Bull. Seism. Soc. Am. 75, 661-675.

Frankel, A. (1984). Source parameters of two $M_{L}=5$ earthquakes near Anza, California, and a comparison with an Imperial Valley aftershock, Bull. Seism. Soc. Am. 74, 1509-1527.

Futterman, W. I. (1962). Dispersive body waves, J. Geophys. Res. 67, 5279-5291.

Haar, L. C., J. B. Fletcher, and C. S. Mueller (1984). The 1982 Enola, Arkansas, swarm and scaling of ground motion in the eastern United States, Bull. Seism. Soc. Am. 74, 2463-2482.

Hanks, T. C. and R. McGuire (1981). The character of high-frequency strong ground motion, Bull. Seism. Soc. Am. 71, 2071-2095.

Hartzell, S. H. (1980). Faulting process of the May 17, 1976 Gazli, USSR earthquake, Bull. Seism. Soc. Am. 70, 1715-1736.

Hartzell, S. H. and T. H. Heaton (1983). Teleseismic mechanism of the May 2, 1983 Coalinga, California, earthquake from long-period body waves, in The 1983 Coalinga, California earthquakes, California Department of Conservation, Division of Mines and Geology, Special Publication 66, 241-246.

Hasegawa, H. S. and R. J. Wetmiller (1980). The Charlevoix earthquake of 19 August 1979 and its seismo-tectonic environment, Earthquake Notes 51, $23-37$.

Heaton, T. H. (1982). The 1971 San Fernando earthquake: a double event?, Bull. Seism. Soc. Am. 72, $2037-2062$.

Heaton, T. H. and D. V. Helmberger (1978). Predictability of strong ground motion in the Imperial Valley: modeling the $M 4.9$, November 4, 1976 Brawley earthquake, Bull. Seism. Soc. Am. 68, 3148.

Helmberger, D. V. and S. D. Malone (1975). Modeling local earthquakes as shear dislocations in a layered half space, $J$. Geophys. Res. 80, 4881-4888.

Helmberger, D. V. and L. R. Johnson (1977). Source parameters of moderate size earthquakes and the importance of receiver crustal structure in interpreting observations of local earthquakes, Bull. Seism. Soc. Am. 67, 301-313.

Helmberger, D. V. and G. R. Engen (1980). Modeling the long-period body waves from shallow earthquakes at regional ranges, Bull. Seism. Soc. Am. 70, 1699-1714.

Herrmann, R. B. (1979). Surface-wave focal mechanisms for eastern North American earthquakes with tectonic implications, J. Geophys. Res. 84, 3543-3552.

Herrmann, R. B., C. A. Langston, and J. E. Zollweg (1982). The Sharpsburg, Kentucky, earthquake of 27 July 1980, Bull. Seism. Soc. Am. 72, 1219-1239.

Johnson, L. R. and T. V. McEvilly (1974). Near-field observations and source parameters of central California earthquakes, Bull. Seism. Soc. Am. 64, 1855-1886.

Kanamori, H. and D. L. Anderson (1975). Theoretical basis of some empirical relations in seismology, Bull. Seism. Soc. Am. 65, 1073-1095.

Kanamori, H. and C. R. Allen (1986). Earthquake repeat time and average stress drop, in Earthquake Source Mechanics, Geophysical Monograph 37, (Maurice Ewing Series 6), American Geophysical Union, Washington, D.C., 227-235.

Kristy, M. J., L. J. Burdick, and D. W. Simpson (1980). The focal mechanisms of the Gazli, USSR earthquakes, Bull. Seism. Soc. Am. 70, 1737-1750.

Langston, C. A. (1976). A body wave inversion of the Koyna, India earthquake of December 10, 1967, and some implications for body wave focal mechanisms, J. Geophys. Res. 81, 2517-2529.

Langston, C. A. (1978). The February 9, 1971 San Fernando earthquake: a study of source finiteness in teleseismic body waves, Bull. Seism. Soc. Am. 68, 1-29.

Langston, C. A. and D. V. Helmberger (1975). A procedure for modeling shallow dislocation sources, Geophys. J. Roy. Astr. Soc. 42, 117-130.

Langston, C. A. and R. Butler (1976). Focal mechanism of the August 1, 1975 Oroville earthquake, Bull. Seism. Soc. Am. 66, 1111-1120.

Liu, H.-L. and H. Kanamori (1980). Determination of source parameters of mid-plate earthquakes from the waveforms of body waves, Bull. Seism. Soc. Am. 70, 1989-2004.

Liu, H.-L. and D. V. Helmberger (1983). The near-source ground motion of the 6 August 1979 Coyote Lake, California, earthquake, Bull. Seism. Soc. Am. 73, 201-218. 
Nábělek, J. L. (1984). Determination of earthquake source parameters from inversion of body waves, Ph.D. Thesis, Massachusetts Institute of Technology, Cambridge, Massachusetts, 361 pp.

Niazi, M. and H. Kanamori (1981). Source parameters of the 1978 Tabas and 1979 Qainat, Iran, earthquakes from long-period surface waves, Bull. Seism. Soc. Am. 71, 1201-1213.

Nowack, R. L. and D. M. Boore (1986). Body wave modeling of the Ceres, South Africa earthquake of September 29, 1969 (submitted for publication).

Nuttli, O. W. (1983a). Empirical magnitude and spectral scaling relations for mid-plate and plate-margin earthquakes, Tectonophysics 93, 207-223.

Nuttli, O. W. (1983b). Average seismic source-parameter relations for mid-plate earthquakes, Bull. Seism. Soc. Am. 73, 519-535.

Scholz, C. H., C. A. Aviles, and S. G. Wesnousky (1985). Scaling differences between large interplate and intraplate earthquakes, Bull. Seism. Soc. Am. 76, 65-70.

Somerville, P. G. (1986). Source scaling relations of eastern North American earthquakes, Report to the Electric Power Research Institute, Palo Alto, California.

Stauder, W. and O. W. Nuttli (1970). Seismic studies: south central Illinois earthquake of November 9 , 1968, Bull. Seism. Soc. Am. 60, 973-981.

Stierman, D. J. and W. J. Ellsworth (1976). Aftershocks of the February 21, 1973 Point Mugu, California earthquake, Bull. Seism. Soc. Am. 66, 1931-1952.

Street, R. L. and F. T. Turcotte (1977). A study of northeastern North American spectral moments, magnitudes and intensities, Bull. Seism. Soc. Am. 67, 599-614.

Street, R. L., R. B. Herrmann, and O. W. Nuttli (1975). Spectral characteristics of the Lg wave generated by central United States earthquakes, Geophys. J. R. Astr. Soc. 41, 51-63.

Suarez, G., L. Seeber, C. Aviles, E. Schlesinger-Miller, and Nábělek, J. L. (1984). The Goodnow, NY earthquake: results from a broadband analysis, abstract, EOS 65, 239-240.

Toksöz, M. N. and J. J. Pulli (1985). Source and path effects for northeastern U.S. earthquakesImplications for earthquake hazards, U.S. Geol. Surv., Open-File Rept. 85-22.

Wallace, T. C. (1983). Long period regional body waves, Ph.D. Thesis, California Institute of Technology, Pasadena, California.

Wallace, T. C., D. V. Helmberger, and G. R. Mellman (1981a). A technique for the inversion of regional data in source parameter studies, $J$. Geophys. Res. 86, 1679-1685.

Wallace, T. C., D. V. Helmberger, and J. E. Ebel (1981b). A broadband study of the 13 August 1978 Santa Barbara earthquake, Bull. Seism. Soc. Am. 71, 1701-1718.

Woodward-Clyde Consultants (1979). Report on the evaluation of maximum earthquake and site ground motion parameters associated with the offshore zone of deformation, San Onofre nuclear generating station, Appendix E, prepared for Southern California Edison, Rosemead, California.

York, D. (1966). Least squares fitting of a straight line, Can J. Phys. 44, 1079-1086.

WoodwaRd-Clyde Consultants

566 EL DoRADo STREET

Pasadena, CAlifornia 91101

(P.G.S., J.P.M., R.W.B.)

\author{
SEISMOLOGICAL LABORATORY \\ California Institute of Technology \\ Pasadena, California 91101 \\ (L.V.L., D.V.H.)
}

Manuscript received 25 February 1986 